\title{
CHARACTERIZATION OF REGENERATED CELLULOSE PREPARED FROM DIFFERENT PULP GRADES USING A GREEN SOLVENT
}

\author{
INDRASENA GHOSH, QASEEM HAIDER and CHHAYA SHARMA \\ Department of Paper Technology, IIT Roorkee, Saharanpur Campus, \\ Saharanpur-247001, Uttar-Pradesh \\ $\bowtie$ Corresponding authors: C. Sharma, Chhaya1964@ rediffmail.com \\ I. Ghosh, indrasenaghosh@gmail.com
}

Received March 9, 2019

\begin{abstract}
The cellulosic polysaccharide shows many potential applications due to its abundance, renewability, biodegradability and biocompatibility. Nowadays, the dissolution of this biopolymer via the alkaline based green solvent system has gained much attention in developing cellulose based composites for pharmaceuticals, waste water treatment or packaging applications. In this work, we aim at dissolving different grades of sustainable pulps in an aqueous $\mathrm{NaOH} /$ urea/thiourea system, involving the freeze thawing process, followed by re-precipitation with distilled water. This particular dissolving medium is chosen as it is economic and environment-friendly. Optical microscopy is used to study the extent of cellulose solubility in this system. Dissolving grade pulp (D.G.P.), with a degree of polymerization $\mathrm{DP}=678.27$, exhibits higher solubility after 3 freeze thawing cycles, compared to bleached hardwood pulp (B.G.P., DP $=990.67$ ) and tissue grade pulp (T.G.P., DP = 1356.54). DP is further correlated with the average fibre length of the three samples obtained from a Morfi fibre analyser. Additionally, fibre identification through the microscopic slide staining procedure reveals that the long flexible softwood fibres present in the T.G.P. sample are responsible for its high DP. The solubility percentage calculated for D.G.P., B.G.P. and T.G.P. is $72.90 \%, 57.2 \%$ and $57 \%$, respectively. The flow behaviour of each dissolved cellulosic sample is of Newtonian type at high shear rates, considering the same cellulose concentration at ambient temperature. X-ray diffraction patterns (XRD) and ATR-FTIR spectra indicate that the ordered crystalline structure of the samples is successfully destroyed and converted to cellulose II during the dissolution and regeneration process. Field emission scanning electron microscopy (FE-SEM) reveals porous structures for all samples, created due to phase separation of the cellulose solutions during regeneration with distilled water. Thus, the key finding of the study establishes that the regeneration via the green solvent can produce more amorphous cellulosic materials, which may be a suitable additive for papermaking, due to their enhanced bonding ability with wood fibres.
\end{abstract}

Keywords: pulp, green solvent, regeneration, solubility, crystalline, degree of polymerization (DP)

\section{INTRODUCTION}

In our modern society, many consumable commercial products are manufactured from synthetic polymers. These non-renewable and non-biodegradable resources have limitations in terms of their inadequate availability and serious environmental pollution. Therefore, much attention has been devoted to replacing these synthetic polymer based materials with naturally occurring inexhaustible bio-based products as a solution for sustainable development and wild life preservation. ${ }^{1,2}$

Nowadays, the utilization of cellulose from different sources has become a subject of intense study, due to its superior mechanical strength, biocompatibility, hydrophilicity, biodegradability, chemical and thermal stability. ${ }^{3-5}$ In spite of holding these outstanding qualities, the presence of inter- and intra-hydrogen bonds between the chains makes cellulose insoluble in aqueous medium, which ultimately limits the polymer's application. Many derivatizing and nonderivatizing solvents have been explored by researchers for dissolving cellulose in order to expand its commercialization. ${ }^{6}$ Regenerated cellulose (RC) is prepared by dissolving cellulose in a suitable solvent and re-precipitating it in a coagulation bath. The solvents that are used to produce RC fibres through viscous routes are 
cuen, cuaxam, cadoxen, which present some disadvantages, such as evolution of toxic gases $\left(\mathrm{H}_{2} \mathrm{~S}, \mathrm{CS}_{2}\right){ }^{1}$. Recently, Lyocell fibres have been developed via dissolving cellulose in a green solvent, N-methylmorpholine-N-oxide/water system. However, this process also has some drawbacks, such as requirement of elevated temperature, formation of by-products and high operating costs. From an economic point of view, this system has still not taken the place of the viscous technique of fabricating $\mathrm{RC}$ fibres. ${ }^{7}$ Other solvents include ionic liquids, N,Ndimethylacetamide, lithium chloride/dimethylacetamide. ${ }^{6} \quad$ The constraints observed by different scientists while studying the dissolution of cellulose in the solutions above make them reconsider the dissolution of cellulose in a more economic and a greener way. Therefore, cellulose dissolution in aqueous alkaline systems at low temperatures, preferably below the freezing point, has been proposed by several authors. ${ }^{8-14}$ They have observed that the solubility percentage of cellulose greatly increased with the addition of additives, such as urea or thiourea, to $\mathrm{NaOH} /$ water binary systems, compared to the dissolution in only $\mathrm{NaOH} /$ water systems. ${ }^{7,15,16}$ They concluded that additives, alkali and water form intermediate complexes through the formation of hydrogen bonds with cellulosic macromolecules, with the destruction of the interand intra-hydrogen bonds existing in native cellulose and result in faster and more dynamic self-assembly of the cellulose molecules. These solutions are quite stable at low to ambient temperatures and maximum solubility depends on the source, degree of polymerization (DP) and the weight percentage of the additives in the alkaline medium. ${ }^{2,12}$ Previour research suggests that the combination of urea and thiourea, along with $\mathrm{NaOH} /$ water, is a promising solvent, which can dissolve cellulose with a higher DP, that is DP > 1200. A rapid progress in various applications of this method of cellulose processing has been observed and industrial trials have also been carried out. $^{12}$ Much effort has been given in preparing regenerated cellulose fibres, biodegradable packaging films, hydrogels, aerogels, microporous membranes from the dissolved solution. ${ }^{5,12,17,18}$ Though regenerated cellulose/inorganic composites have been explored in many fields, such as waste water treatment, papermaking, separation technology and biomedical applications, ${ }^{4,17,19,20}$ yet their applications in papermaking chemistry have not been fully investigated. Most research has focused on the utilization of cotton and non-wood based raw material as a source of cellulose for developing RC fibres. There is very limited literature available on the dissolution of wood pulp in this novel solvent. ${ }^{12}$

The goal of the present work has been to understand the dissolution characteristics of pulp grades obtained from three different sustainable paper products, such as rayon grade paper, bleached handmade sheets from hardwood and tissue paper, in the $\mathrm{NaOH} /$ urea/thiourea/water system. RC produced from a dissolved cellulose solution was further characterized in terms of crystallinity, structural properties, as well as flow behaviour at ambient temperature. This study is a first step in evaluating the potential of the obtained regenerated cellulose for its application as one of the papermaking additives, which will be continued in further studies.

\section{EXPERIMENTAL}

\section{Materials}

Rayon grade/dissolving grade paper and laboratory-made handsheets from bleached hardwood pulp were supplied by a local paper mill. Tissue paper was purchased from a local market. Sodium hydroxide $(\mathrm{NaOH})$, urea $\left(\mathrm{CONH}_{2}\right)$ and thiourea $\left(\mathrm{CONH}_{2} \mathrm{~S}\right)$ used in the study were of analytical grade. Distilled water was used as coagulation bath for preparing regenerated cellulose. All the samples were shredded into small pieces, disintegrated at $3000 \mathrm{rpm}$ for $15 \mathrm{~min}$ and squeezed to remove water. Finally, the pulps were vacuum dried at $60{ }^{\circ} \mathrm{C}$ before further treatment. The pulps were then coded as D.G.P. for rayon grade pulp, B.G.P. for handsheets and T.G.P. for tissue paper.

\section{Preparation of regenerated cellulose}

A certain amount of dried pulp was dispersed in $8 \% \mathrm{NaOH} / 8 \%$ urea/6.5\% thiourea/water system ${ }^{7}$ for 30 min, with a Remi mechanical stirrer, and the slurry was stored in a refrigerator at $-10{ }^{\circ} \mathrm{C}$ for $12 \mathrm{~h}$. The frozen sample was then taken out and vigorously stirred in an ice bath at $0{ }^{\circ} \mathrm{C}$ for $5 \mathrm{~min}$ and then thawed at $25^{\circ} \mathrm{C}$ for $1 \mathrm{~h}$. The procedure was repeated thrice to obtain a solution of $1 \%$. Further, the mixture was centrifuged at $8000 \mathrm{rpm}$ at $10{ }^{\circ} \mathrm{C}$ for degassing and to remove undissolved the cellulose gel. ${ }^{5}$ Finally, the dissolved cellulose was precipitated with excess distilled water to produce regenerated cellulose, which was then washed several times with water. It was then centrifuged and air dried for further characterization.

\section{Characterization}

\section{Degree of polymerization (DP)}

The degree of polymerization of the pulp samples was calculated based on the intrinsic viscosity 
measurements. Intrinsic viscosity was measured by utilizing a capillary viscometer for dissolved pulp samples in cupriethylene diamine hydroxide (CED)/water solutions (CUEN) at $25{ }^{\circ} \mathrm{C}$, according to the TAPPI method T230 om-04. The degree of polymerization was then calculated from the following equation: ${ }^{21}$

$$
D P^{0.85}=1.1 \times \eta
$$

where $\eta$ corresponds to intrinsic viscosity.

\section{Fibre characterization}

Each diluted suspension of pulp samples was disintegrated for fibre characterization by a Morfi fibre analyzer (Techpap, France) in terms of length, width, coarseness, kinks, curls and shives. The software uses a camera for image analysis to evaluate the above characteristics. Further, the dispersed fibres from each sample were analysed for the determination of hardwood/softwood fibre origin on microscopic slides according to the method ISO 9184-1: 1990. The analysis required $0.05 \%$ concentration of softened fibre suspension, from which $0.5 \mathrm{~mL}$ of the solution was pipetted out on the slides mounted on a hot plate. The slides were then stained with Graff $\mathrm{C}$ stain for fibre identification and classification according to their morphology under a light microscope.

\section{Solubility test}

Generally, the cellulose solubility test is performed to understand the dissolution properties in any solvent. ${ }^{7}$ In our experiment, $0.2 \mathrm{~g}$ of each pulp sample was dispersed in a total of $20 \mathrm{~g}$ of the solvent. After the freeze thawing process, the undissolved cellulose residue was isolated by centrifugation, washed until free of $\mathrm{NaOH} /$ urea/thiourea and finally dried in an oven for calculating the cellulose mass. Meanwhile, the dissolved cellulose mass was calculated after precipitation with water, followed by drying. The extent of solubility was calculated according to the equation:

$$
\mathrm{S}=\frac{A}{A+B} \times 100
$$

where $\mathrm{S}$ is the solubility in $\%, \mathrm{~A}$ and $\mathrm{B}$ are the dissolved pulp and undissolved cellulose mass, respectively, in grams. Further, direct dissolution of the pulp samples could be analyzed with a polarized optical microscope, Leica DM2500, initially and after three freeze thawing cycles at a magnification of $10 \mathrm{X}$.

\section{Rheological properties}

The flow behaviour of each dissolved pulp sample in the $\mathrm{NaOH} /$ urea/thiourea/water system was observed by examining its viscosity via a rheometer (MCR-102 ANTON PAAR, USA). The sample was placed between $35 \mathrm{~mm}$ parallel plates at $25^{\circ} \mathrm{C}$, at a shear rate ranging from $0.05 \mathrm{~s}^{-1}$ to $500 \mathrm{~s}^{-1}$. The experiment was carried out in the steady state mode.

\section{Wide angle $X$-ray diffraction (XRD)}

Regenerated cellulose was dried at $60{ }^{\circ} \mathrm{C}$ overnight and ground to powder before XRD analysis for comparing the crystalline phases of the native and treated pulp samples. Diffraction patterns were obtained by a WAXD (Rigaku Ultima IV) X-ray diffractometer, operating at $40 \mathrm{kV}$ and $30 \mathrm{~mA}$ over a range of $2 \theta=5^{\circ}-30^{\circ}$, at a scan rate of $4 \% \mathrm{~min}$. The radiation source was Nickel filtered $\mathrm{CuK} \alpha(\lambda=1.5406$ $\AA$ ). The crystallinity index, CI, of the pulp samples were calculated based on the area method, according to the formula:

$$
C I=\frac{A}{A+B} \times 100
$$

where $\mathrm{A}=$ area under the crystalline diffraction peak, $\mathrm{B}=$ area under amorphous diffraction peak.

\section{Attenuated total reflectance - Fourier-transform infrared spectroscopy (ATR-FTIR)}

FTIR spectra of different pulp samples and films of regenerated cellulose were obtained via an ATR sampling accessory equipped with zinc selenide ( $\mathrm{ZnSe}$ ), at an incident angle of $45^{\circ}$ on a Perkin Elmer 1600 spectrophotometer. 16 scans were recorded at a resolution of $4 \mathrm{~cm}^{-1}$ to acquire the absorption spectra between 4000 and $500 \mathrm{~cm}^{-1}$.

Field emission scanning electron microscopy (FESEM)

The surface morphology of the native and regenerated cellulose was examined by a TESCAN MIRA 3 Field Emission Scanning Electron Microscope. Before analysis, dried samples mounted on aluminium stubs were sputtered with gold for 10 min. Images were taken at a magnification of $1 \mathrm{kX}$ and $15 \mathrm{kX}$, with an accelerating voltage between $6 \mathrm{kV}-8$ $\mathrm{kV}$.

\section{RESULTS AND DISCUSSION}

The properties of the pulp samples are depicted in Table 1. The intrinsic viscosity, $\eta$ (231.9 $\mathrm{mL} / \mathrm{g}$ ) and the corresponding DP (678) of bleached D.G.P., as evident from Table 2, are much lower than the intrinsic viscosity of T.G.P. (418 mL/g), with DP 1365, calculated in CED/water solutions. The critical value of $\eta$ for dissolving grade pulp to manufacture high quality viscose rayon should not be less than $200 \mathrm{~mL} / \mathrm{g}$, which is in agreement with our results. ${ }^{22}$ The lower viscosity of D.G.P. is caused by the processing conditions during pre-extraction, pulping and bleaching of the pulp and generally depends upon the pre-extraction method.

During the extraction process, either prehydrolysis kraft pulping, hot or cold water extraction or enzymatic treatment, most of the 
wood components, mainly hemicelluloses (xylan), are removed to get highly purified pulp with $90 \%$ cellulose content. In almost all the cases, a decrease in the intrinsic viscosity of pulp was observed, with a lower amount of xylan, as well as lignin content. ${ }^{22-24}$ The removal of hemicelluloses and subsequent peeling reactions in alkaline pulping resulted in the degradation of cellulosic chains. This happened because of the cleavage of glycosidic bonds, resulting in lower pulp viscosity in bleached dissolving grade pulp, compared to bleached pulp without any preextraction stage. ${ }^{24,25}$ The intrinsic viscosity is the hydrodynamic volume occupied by a given polymer mass, which reflects the ability of a polymer in a solution to increase the solution viscosity without any intermolecular interactions. ${ }^{26}$ Several theories suggest that, in the case of linear polymeric macromolecules, this value is related either to its molecular weight or to the degree of polymerization. It can also correlate other molecular properties, such as radius of gyration, pore size, polymer conformation or overlap concentrations of polymeric chains. ${ }^{26-28}$ The value of $\eta$ generally defines the dimension and flexibility of individual polymer chains in a good solvent. ${ }^{7}$ In a good solvent, an individual polymer coil is well solvated with an extended conformation, preventing the polymer from selfassociation and contraction. Thus, it has been proved to be an essential parameter for determining the solution properties of polymeric macromolecules in different solvents. ${ }^{26,27}$

Since cuen is a widely used solvent for cellulose dissolution and determination of the intrinsic viscosity, the value of $\eta$ for D.G.P., B.G.P. and T.G.P. implies the contribution of each coiled chain to the whole solution rheology. ${ }^{26,29,30}$ Moreover, the corresponding DP indicates the size of the polymer chains, which is a piece of evidence that T.G.P. contains more flexible and some long cellulosic fibre chains, which are stiffer compared to D.G.P, and B.G.P. ${ }^{7,31}$ The DP of the cellulose polymer chains can be well correlated with the average fibre length of the samples, as depicted in Table 2. The arithmetic fibre length, as well as the mean fibre length, is comparatively higher for the sample with higher DP, i.e., T.G.P. It has been well established in the literature that the mean fibre length is linearly dependent on the cellulose DP for different paper samples and can indicate certain conditions in the case of printing papers and books. ${ }^{32}$ Moreover, the fibre length distribution depicted in Figure 1 reveals that D.G.P. contains the highest percentage of short fibre fractions and the lowest percentage of long fibres, whereas the fibre characteristics of T.G.P. shows the existence of a higher proportion of long fibres. On the other hand, B.G.P. exhibits the narrowest length distribution. A much broader distribution can be found in the case of T.G.P. The results clearly indicate that the T.G.P. samples are the most heterogeneous in terms of fibre length, compared to B.G.P. and D.G.P. Therefore, this approach is a reliable, accurate and faster analytical tool, which provides important characteristics of the pulp samples, as suggested by many researchers. ${ }^{32-34}$

Additionally, microscopic analysis for investigating the fibre sources utilized for the preparation of the three pulp grades were further carried out.

The intense blue, violet or light brownish colours in the images from Figure 2 depict that all the bleached samples were processed through chemical pulping since Graff $\mathrm{C}$ stain did not react to give any yellow colour. Yellow colour generally represents unbleached chemical, semichemical or mechanical pulping. ${ }^{35,36}$

Table 1

Properties of different pulp samples

\begin{tabular}{lccc}
\hline Parameter & D.G.P. & B.G.P. & T.G.P. \\
\hline Mean fibre length $(\mathrm{mm})$ & 0.685 & 0.752 & 1.132 \\
Average fibre width $(\mu \mathrm{m})$ & 17.2 & 14.5 & 23.1 \\
Coarseness $(\mathrm{mg} / \mathrm{m})$ & 0.024 & 0.0248 & 0.0451 \\
Curl $(\%)$ & 11.3 & 8.6 & 9 \\
Ratio in length of macrofibrils $(\%)$ & 0.727 & 0.475 & 1.06 \\
Fine elements $(\%$ in length) & 24 & 29.2 & 40.4 \\
Total fibres & 5058 & 5251 & 5018 \\
\hline
\end{tabular}


Cellulose

Table 2

Characteristics of fibres from different pulp grades

\begin{tabular}{lccccccc}
\hline Sample & $\begin{array}{c}\eta_{\text {int }} \\
(\mathrm{mL} / \mathrm{g})\end{array}$ & DP & $\begin{array}{c}\text { Solubility } \\
(\%)\end{array}$ & $\begin{array}{c}\text { CI of NA } \\
\text { pulp }(\%)\end{array}$ & $\begin{array}{c}\text { CI of RG } \\
\text { pulp }(\%)\end{array}$ & $\begin{array}{c}\text { LOI of } \\
\text { NA pulp } \\
1430 / 897\end{array}$ & $\begin{array}{c}\text { LOI of } \\
\text { RG pulp } \\
1430 / 897\end{array}$ \\
\hline D.G.P. & 231.9 & 678.27 & 75 & 80 & 57 & 1.25 & 0.93 \\
B.G.P. & 320 & 990.67 & 57.2 & 72 & 45 & 1.07 & 0.47 \\
T.G.P. & 418 & 1356.54 & 57 & 48 & 21 & 0.82 & 0.33
\end{tabular}

$\eta_{\text {int }}=$ intrinsic viscosity, DP = Degree of polymerizatio; $\mathrm{CI}=$ Crystallinity index; LOI $=$ Lateral order index NA = Native; $R G=$ Regenerated

Further, it reveals that the vessels in D.G.P. appear as little barrels and are wider than the fibres. B.G.P. vessels are shorter and wider than the D.G.P. vessels. Both types of vessels have bordered pits with large single openings at both ends. The presence of vessels signifies that B.G.P. and D.G.P. samples are made from hardwood fibres. In general, hardwood fibre length varies from 0.7 to $1.7 \mathrm{~mm}$, with a narrow fibre length distribution. $^{37,38}$ On the other hand, T.G.P. contains long single tracheids with ray cells, indicating the presence of softwood fibres, in addition to shorter hardwood fibres. ${ }^{35,38}$ Therefore, it is envisaged that the presence of long fibres in the T.G.P. sample might be the reason for its high intrinsic viscosity and corresponding DP.

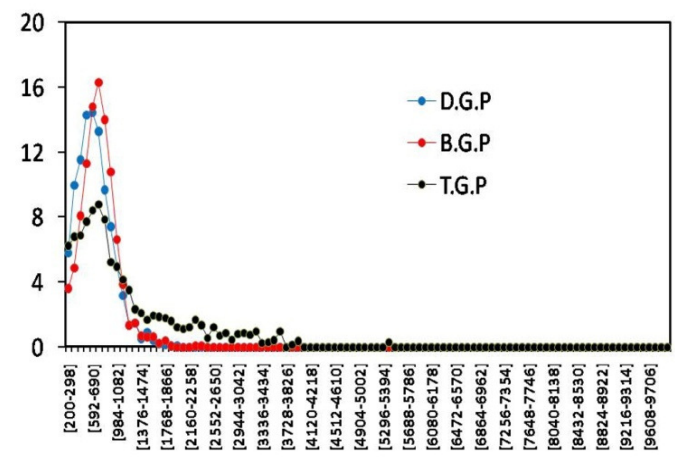

Figure 1: Comparative fibre length distribution of dissolving grade pulp (D.G.P.), bleached grade pulp (B.G.P.) and tissue grade pulp (T.G.P.)

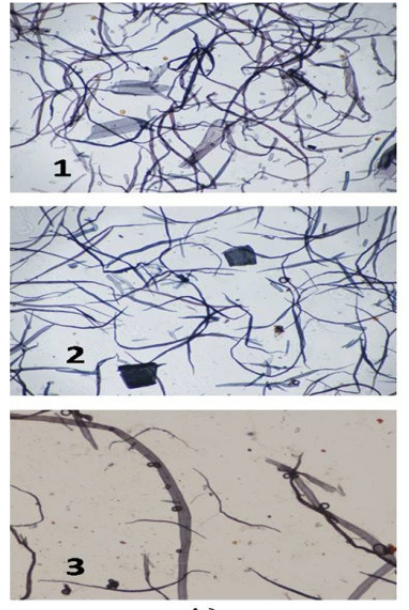

A)

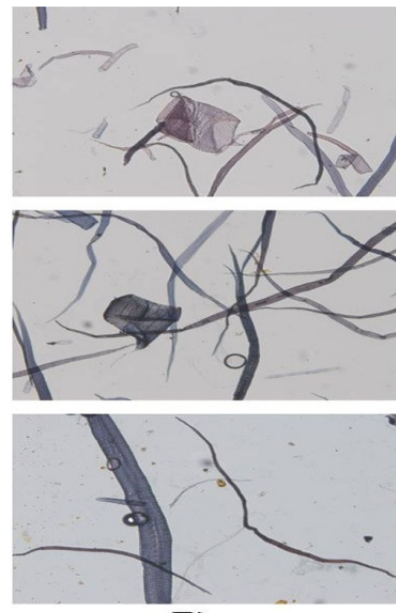

B)

Figure 2: Fibre morphology of different pulp grades; 1) D.G.P., 2) B.G.P., 3) T.G.P., at A) 4x B) 10X 


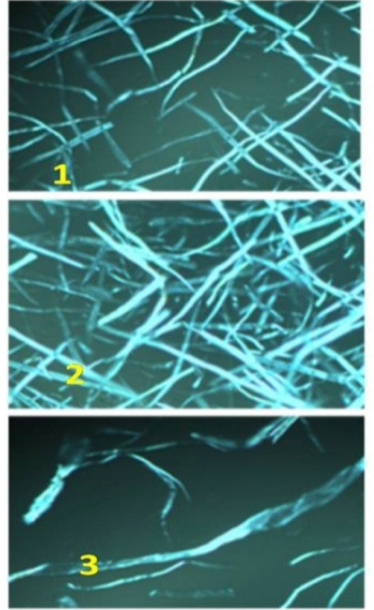

A)
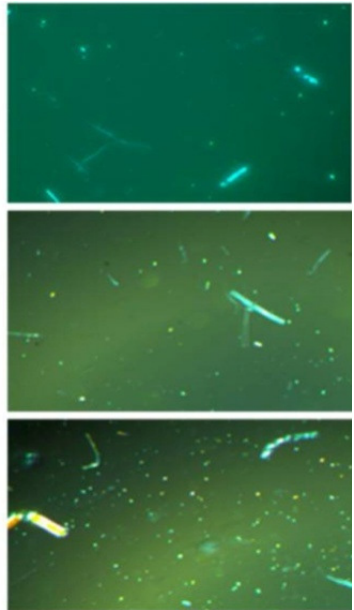

B)

Figure 3: Optical microscopy images of dissolution of different pulp grades; 1) D.G.P., 2) B.G.P., 3) T.G.P., in $\mathrm{NaOH} /$ urea/thiourea/water system A) initially, and B) after 3 freeze thawing cycles

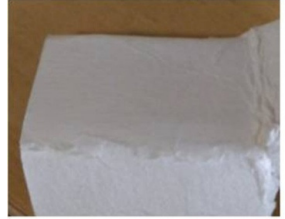

A)

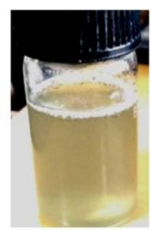

B)

Figure 4: Photographs of A) native dissolving grade pulp (D.G.P.), B) dissolved cellulose (D.G.P.) after treatment

As expected, the solubility of D.G.P. (75\%) in $\mathrm{NaOH} /$ urea/thiourea was the highest among the three pulp grades studied. Figure 3 shows the optical images of the dissolution of D.G.P., B.G.P. and T.G.P., initially and after 3 freeze thawing cycles in the green solvent. Initially, all the pulp samples dispersed in the solvent conserved their intact morphological characteristics. In contrast, the study reveals that the dissolution power of each pulp remarkably increased after the 3 cycles of freeze thawing, indicating that almost $60 \%$ solubility was achieved even for high DP samples. Therefore, it can be concluded that the additives and $\mathrm{NaOH}$ might have successfully destroyed the intra- and inter-hydrogen bonding of the macromolecule through the formation of some inclusion complexes, resulting in rapid swelling and dissolution of the fibres. In previous literature, this system $(\mathrm{NaOH} /$ urea/thiourea/water) has been proved to be a universally accepted solvent for cellulose dissolution, with low or high DP, at low temperature below the freezing point. ${ }^{2,7}$ Photographs of the native D.G.P. and of the clear solution after its dissolution are depicted in Figure 4.

As seen in Figure 5A, clear solutions of D.G.P. and B.G.P. dissolved in $\mathrm{NaOH} /$ urea/thiourea/ water exhibit slightly shear-thinning behaviour below low shear rate $\left(100 \mathrm{~s}^{-1}\right)$, but tend to behave as Newtonian fluids at high shear rates $\left(100 \mathrm{~s}^{-1}\right.$ $500 \mathrm{~s}^{-1}$ ) at $25{ }^{\circ} \mathrm{C}$, suggesting that apparent viscosity is independent of high shear rate. This indicates faster disentanglement of the molecular chains in solutions with sudden external force at low shear rates. Afterwards, the rate of disentanglements is almost similar to the rate of newly formed entangled chains at higher shear rates. In the case of T.G.P., the flow transition from nonlinear to linear is not observed in the whole range of shear rate studied, where in the Newtonian type the flow behaviour can be seen. ${ }^{13}$ It has been reported that dilute solutions of cellulose dissolved in this solvent (NaOH/urea/thiourea/water) show more pronounced Newtonian behaviour with linear trend at $20{ }^{\circ} \mathrm{C}$ rather than at $10{ }^{\circ} \mathrm{C} .{ }^{39}$ The shear stress $v s$. shear rate curve in Figure 5B further 
reveals the linear relationship for all the systems. It is also quite predictable from the graph that viscosity increases with increasing concentration. This is because a higher amount of cellulose was present in the case of D.G.P. solutions, as maximum cellulose solubility was obtained, compared to B.G.P. and T.G.P., as shown in Table 2. Increased viscosity is due to the formation of more hydrogen bonds with the hydroxyl groups of the hydrated molecules of solutes present in the liquid. ${ }^{39}$

It is evident from the XRD results in Figure 6 that native D.G.P., B.G.P. and T.G.P. display a sharp diffraction peak at $2 \theta=22.8^{\circ}$, which corresponds to the crystallographic lattice plane

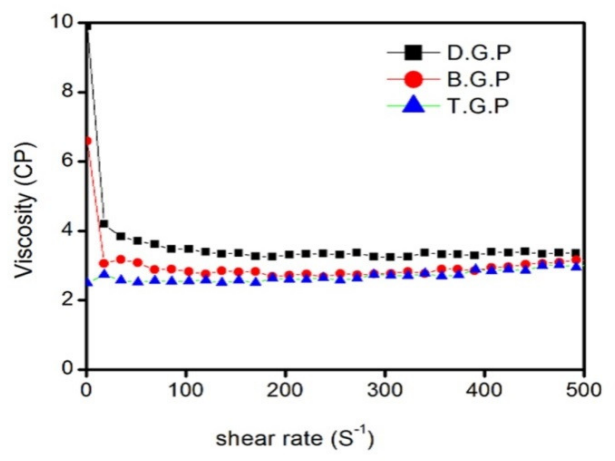

A

Figure 5: A) Viscosity $v s$. shear rate; B) Shear stress $v s$. shear rate for different solutions of pulp grades dissolved in

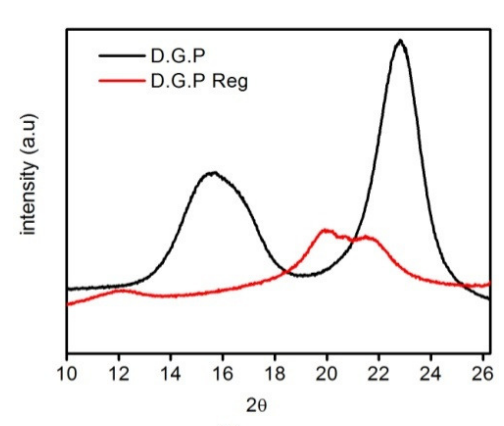

A)
(200) for cellulose I. The two overlapped weaker diffraction peaks at $2 \theta=15.1^{\circ}$ and $16.6^{\circ}$ can also be identified, resembling the planes (1) 0$)$ and (110), respectively. ${ }^{2}$ The characteristic peaks exhibited by the $\mathrm{NaOH} /$ urea/thiourea treated native D.G.P. and B.G.P. are $2 \theta=12.1^{\circ}, 19.9^{\circ}$ and $21.6^{\circ}$, which are assigned to the planes (1) 0 ), (100) and (200), respectively. These peaks are attributed to the typical cellulose II diffraction pattern. ${ }^{5}$ In the case of T.G.P., no distinguished crystallographic peaks are observed at $2 \theta=19.9^{\circ}$ and $21.6^{\circ}$. Instead, a broad scattering peak centered at $20.97^{\circ}$ is observed, suggesting that cellulose crystals have been amorphized.

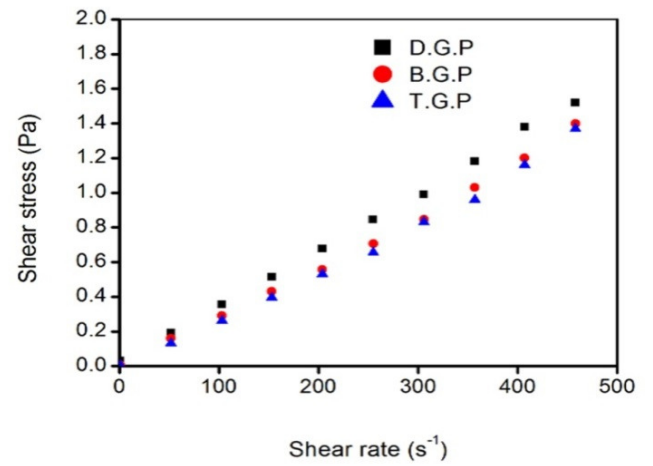

$B$

\section{$\mathrm{NaOH} /$ urea/thiourea/water at $25^{\circ} \mathrm{C}$}

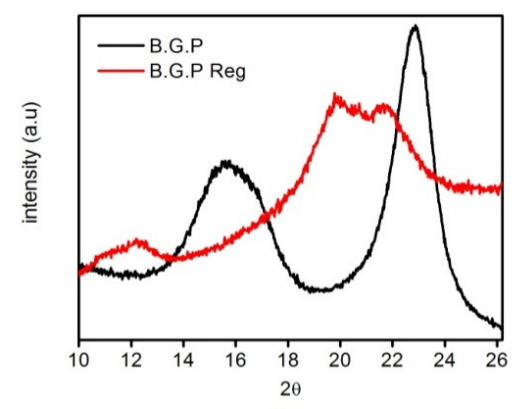

B)

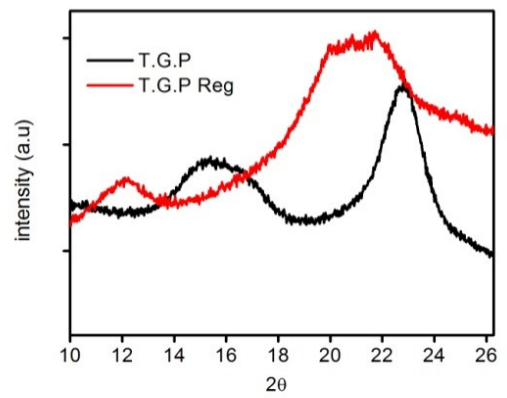

C)

Figure 6: XRD patterns of native and regenerated pulp samples 


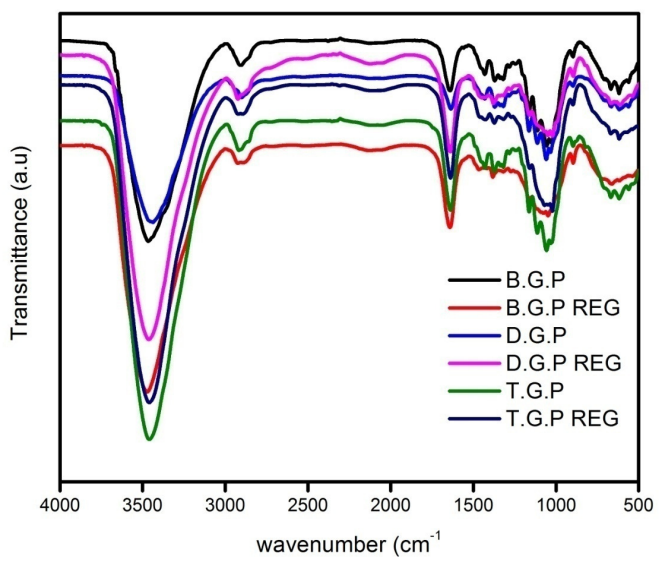

Figure 7: FTIR patterns of native and regenerated pulp samples

Again, the crystallinity index $(\mathrm{CI})$ of treated D.G.P. and B.G.P. has sufficiently decreased, as evident from Table 2. The results reveal that all the native cellulose (type I polymorph) was converted to cellulose II (type II polymorph) by disrupting the crystalline domains during dissolution and regeneration process. In this system, $\mathrm{NaOH}$ was supposed to act as inter- and intra-hydrogen bond breaker, resulting in swelled cellulose. The addition of inorganic salts, urea and thiourea, then might have stabilized the alkali solution, preventing the cellulose strands from further aggregation. The formation of new hydrogen bonds takes place between the hydroxyl groups in the cellulose- $\mathrm{NaOH}$ complex and amine or carbonyl groups in salts. Thus, the emergence of new inclusion complexes favoured a good dissolution of cellulose in the solvent and the regeneration in the coagulating bath lead to the formation of cellulose II. This theory has been supported by many authors. ${ }^{40}$ The lower crystallinity of T.G.P. implies that more random orientation of inter- and intra- molecules are present rather than packed chain structures, compared to other two pulp grades. As expected, the decrease in crystallinity for D.G.P. is low, compared to the other two pulps, as this pulp grade possesses higher crystallinity in native state, due to its lower content of hemicellulose. ${ }^{19}$

Infrared spectral analysis, which is a common tool for characterization of polymers, was also carried out to study the structural changes in cellulose after regeneration from the abovementioned solvent in the region $4000-500 \mathrm{~cm}^{-1}$, as shown in Figure 7. The cellulose in its native state for each sample possesses similar characteristic peaks, as described below. The peaks in the ranges of $3328 \mathrm{~cm}^{-1}-3333 \mathrm{~cm}^{-1}$ and $1640 \mathrm{~cm}^{-1}$ -
$1647 \mathrm{~cm}^{-1}$ signify the presence of hydroxyl groups. The absorption bands in the region of 110 $\mathrm{cm}^{-1}-1108 \mathrm{~cm}^{-1}$ suggest ether linkages and are assigned to asymmetric ring stretching. The peaks at $1425 \mathrm{~cm}^{-1}-1429 \mathrm{~cm}^{-1}$ are observed due to $\mathrm{CH}_{2}$ asymmetric bending vibrations. Other spectral bands in the ranges $1154 \mathrm{~cm}^{-1}-1158 \mathrm{~cm}^{-1}, 1051$ $\mathrm{cm}^{-1}-1053 \mathrm{~cm}^{-1}, 1331 \mathrm{~cm}^{-1}-1332 \mathrm{~cm}^{-1}, 1304 \mathrm{~cm}^{-1}$. $1360 \mathrm{~cm}^{-1}$ represent $\mathrm{C}-\mathrm{O}$ stretch, $\mathrm{OH}$ bending, $\mathrm{OH}$ in plane, $\mathrm{CH}$ deformation, respectively. In addition, the peak at $894 \mathrm{~cm}^{-1}-898 \mathrm{~cm}^{-1}$ refers to group $\mathrm{C} 1$ frequency. ${ }^{41,42}$

In comparison with the spectrum of native cellulose, i.e. cellulose I, many of the absorption bands between $1425 \mathrm{~cm}^{-1}-898 \mathrm{~cm}^{-1}$ either disappeared or reduced in intensity in the spectrum of regenerated cellulose made from all the pulp grades. This is an indication that the dissolution and the regeneration have transformed the crystalline structure into more amorphous cellulose. Specifically, it is observed that the sharp peaks at $1425 \mathrm{~cm}^{-1}$ and at $1154 \mathrm{~cm}^{-1}$ in cellulose I spectrum have disappeared in the region of $1425 \mathrm{~cm}^{-1}$, appearing as a shoulder at $1154 \mathrm{~cm}^{-1.41,43}$ This implies the reduction in crystallinity and obliteration of intermolecular hydrogen bonds in the regenerated cellulose.

Moreover, the lateral order index, i.e. the absorbance ratio A1430/A897, was calculated to analyze the fraction of cellulose $\mathrm{I}$ in the regenerated samples after the dissolution treatment. It is evident from Table 2 that the LOI of all the cellulose samples has been significantly decreased after regeneration from the $\mathrm{NaOH} /$ urea/thiourea system, which further confirms the existence of cellulose II. $^{3}$ Therefore, the ATR-FTIR results can be correlated well with the XRD patterns of regenerated cellulose, 
confirming that cellulose I has been transformed into cellulose II. $^{43}$

FE-SEM analysis in Figure 8 confirms that T.G.P. contains fibres with more random orientation than D.G.P., which is in agreement with XRD results, indicating lower crystallinity of T.G.P. compared to D.G.P. In addition to this, it is also observed that the morphology of all the regenerated celluloses displays identical asymmetric structures with interconnected networks of fibres. Moreover, the pore formation in the treated samples is ascribed to the phase separation of cellulose in the aqueous coagulation bath. Different authors have explained that this phenomenon generally occurs when faster diffusion of the coagulant (non-solvent) takes place with the removal of the solvent from cellulose solutions. $^{2,5}$
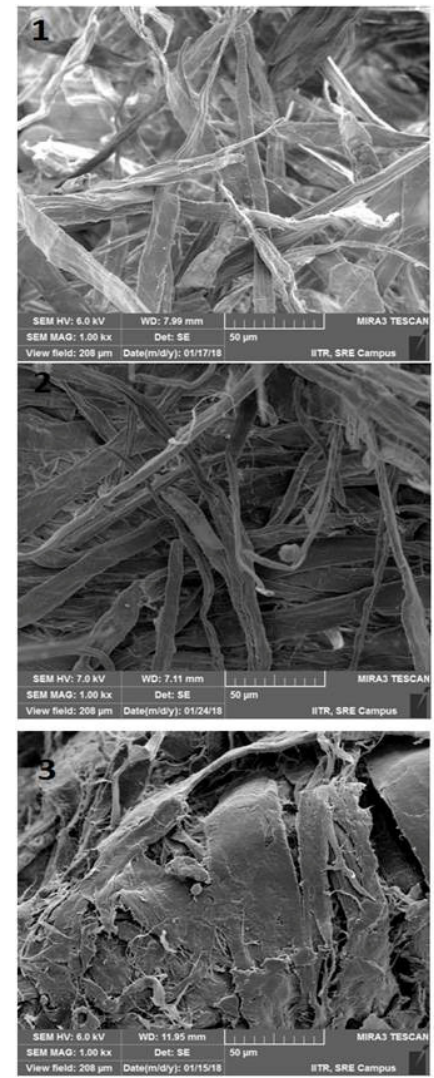

A)

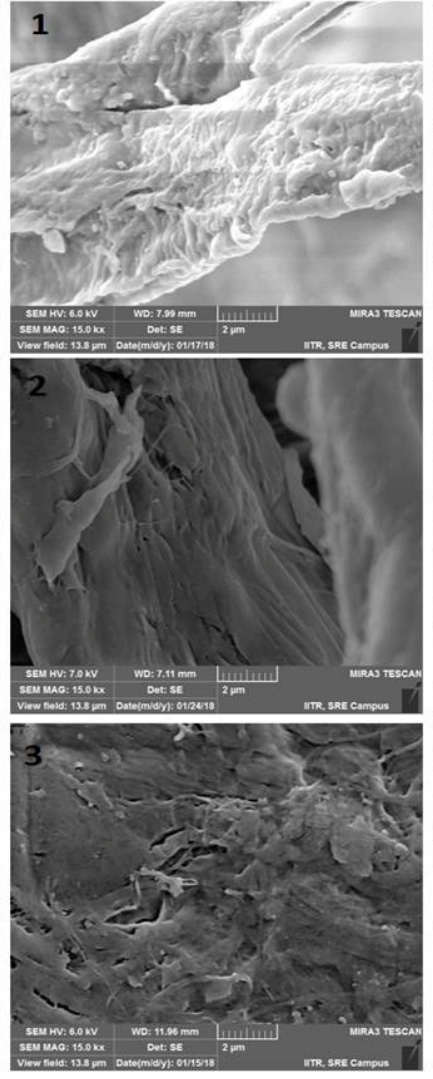

B)

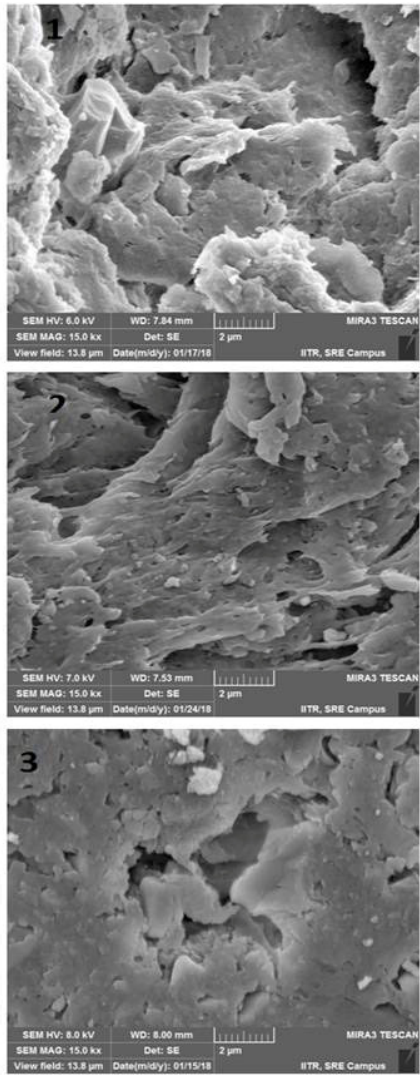

C)

Figure 8: FE-SEM images of A) native pulp samples at magnification 1000x; B) native pulp samples at magnification 15000x; C) regenerated cellulose powders at magnification 15000 x; 1) D.G.P., 2) B.G.P., 3) T.G.P.

\section{CONCLUSION}

In our present study, regenerated celluloses from different sustainable pulp products (dissolving grade, bleached hardwood grade and tissue grade) have been successfully prepared through dissolution of the pulps in a green solvent system. Regenerated cellulose produced from dissolving grade pulp exhibits a higher degree of crystallinity, compared to the other two pulp grades, due to its lower hemicellulose content, as confirmed by XRD results. Moreover, FE-SEM analysis reveals identical morphological characteristics for all the treated cellulosic pulps, with the presence of pores. Also, it is noticeable that the percentage of solubility increases for the cellulosic pulp samples with lower DP. The fact that cellulose can be dissolved via the freeze thawing method is further supported by optical microscopy. The rheological properties imply that the shear viscosity of the dissolving grade pulp is maximum, suggesting a higher concentration of cellulose in its dissolved state due to its higher solubility in this solvent. Moreover, it is observed that all the dissolved pulp solutions behave as 
Newtonian fluids at high shear rate. Therefore, the present results reveal the universality and strong capacity of dissolving cellulose, broadening the scope of its potential applications. From the papermaking point of view, it is expected that regenerated cellulose, with less crystalline domains, should have higher bondability with wood fibres than the native one, which makes it a suitable additive.

ACKNOWLEDGEMENT: The research work was funded by the Ministry of Human Resources and Development, Government of India.

\section{REFERENCES}

1 H. Qi, C. Chang and L. Zhang, Green Chem., 11, 177 (2009), https://doi.org/10.1039/B814721C

2 R. Li, S. Wang, A. Lu and L. Zhang, Cellulose, 22, 339 (2015), https://doi.org/10.1007/s10570-014-05426

3 C. H. Kuo and C. K. Lee, Carbohyd. Polym., 77, 41 (2009), https://doi.org/10.1016/j.carbpol.2008.12.003

4 K. Y. Chong, C. H. Chia, S. Zakaria, M. S. Sajab, S. W. Chook et al., Cellulose, 22, 2683 (2015), https://doi.org/10.1007/s10570-015-0675-2

5 W. Zhang, X. Chen, J. Pan, C. Gao and J. Shen, RSC Adv., $\quad$ 6, $\quad 114750 \quad$ (2016), https://doi.org/10.1039/C6RA18766H

6 S. Sen, J. D. Martin and D. S. Argyropoulos, ACS Sustain. Chem. Eng., 1, $858 \quad$ (2013), https://doi.org/10.1021/sc400085a

S. Zhang, F.-X. Li, J.-Y. Yu and G. Li-Xia, Cellulose Chem. Technol., 43, 241 (2009), http://www.cellulosechemtechnol.ro/pdf/CCT7-82009/p.241-249.pdf

8 A. Isogai and R. H. Atalla, Cellulose, 5, 309 (1998), https://doi.org/10.1023/A:1009272632367

9 J. Zhou and L. Zhang, Polym. J., 32, 866 (2000), https://doi.org/10.1295/polymj.32.866

10 J. Cai and L. Zhang, Macromol. Biosci., 5, 539 (2005), https://doi.org/10.1002/mabi.200400222

11 C. Olsson and G. Westman, in "CelluloseFundamental Aspects", edited by Theo van de Ven and Louis Godbout, IntechOpen, 2013, p. 143, https://doi.org/10.5772/52144

12 S. Zhang, W. Wang, F. Li, J. Yu and S. Zhang, Cellulose Chem. Technol., 47, 671 (2013), http://www.cellulosechemtechnol.ro/pdf/CCT910(2013)/p.671-679.pdf

13 J. Trygg and P. Fardim, Cellulose, 18, 987 (2011), https://doi.org/10.1007/s10570-011-9550-y

14 M. Zdanowicz, K. Wilpiszewska and T. Spychaj, Carbohyd. Polym., 200, $361 \quad$ (2018), https://doi.org/10.1016/j.carbpol.2018.07.078

15 W. Zhang, T. Wang, S. Li, K. Cheng, S. Wei et al., Cellulose Chem. Technol., 51, 911 (2017), http://www.cellulosechemtechnol.ro/pdf/CCT9- 10(2017)/p.911-917.pdf

16 P. Piltonen, N. C. Hildebrandt, B. Westerlind, J.-P. Valkama, T. Tervahartiala et al., Compos. Sci. Technol., $\quad \mathbf{1 3 5}, \quad 153 \quad$ (2016), https://doi.org/10.1016/j.compscitech.2016.09.022

17 D. Ruan, L. Zhang, Y. Mao, M. Zeng and X. Li, J. Membrane Sci., 241, $265 \quad$ (2004), https://doi.org/10.1016/j.memsci.2004.05.019

18 H. Kaco, S. Zakaria, N. F. Razali, C. H. Chia, L. Zhang et al., Sains Malaysiana, 43, 1221 (2014), https://ukm.pure.elsevier.com/en/publications/propertie s-of-cellulose-hydrogel-from-kenaf-core-prepared-viapre

9 X. Qin, A. Lu and L. Zhang, Cellulose, 20, 1669 (2013), https://doi.org/10.1007/s10570-013-9961-z

20 D. L. Morgado, E. Frollini, A. Castellan, D. S. Rosa and V. Coma, Cellulose, 18, 699 (2011), https://doi.org/10.1007/s10570-011-9516-0

21 M. N. I. Setu, M. Y. Mia, N. J. Lubna and A. A. Chowdhury, Dhaka Univ. J. Pharm. Sci., 13, 187 (2014), https://doi.org/10.3329/dujps.v13i2.21899

22 D. Li, D. Ibarra, V. Köpcke and M. Ek, in "Functional Materials from Renewable Sources", edited by F. Liebner, T. Rosenau, ACS Symposium Series, 2012, pp. 167-189, https://doi.org/10.1021/bk2012-1107.ch009

23 M. T. García, A. Alfaro, M. A. M. Zamudio, A. N. A. B. Morales and F. López, Cellulose Chem. Technol., $\quad 51, \quad 465 \quad$ (2017), http://www.cellulosechemtechnol.ro/pdf/CCT56(2017)/p.465-475.pdf

24 M. Borrega, L. K. Tolonen, F. Bardot, L. Testova and H. Sixta, Bioresour. Technol., 135, 665 (2013), https://doi.org/10.1016/j.biortech.2012.11.107

25 M. A. Javed and U. Germgård, BioResources, 6, 2581

(2011) https://bioresources.cnr.ncsu.edu/BioRes_06/BioRes_0 6_3_2581_Javed_G_Reactivity_Prehyd_Kraft_Chlorit e_Delig_1652.pdf

${ }^{26}$ D. Wandel, M. Johan and H. Marie, in Procs. Annual Transactions of the Nordic Rheology Society, $21^{\text {st }}$ Nordic Rheology Conference, the Nordic Rheology Society, Copenhagen, DK, June 12-14, 2013, p. 255, https://www.tib.eu/en/search/id/ceaba\%3ACEAB2013 1101801/Use-of-intrinsic-viscosity-for-evaluation-ofpolymer/

27 J. Lee and A. Tripathi, Anal. Chem., 77, 7137 (2005), https://doi.org/10.1021/ac050932r

28 P. Debye and A. M. Bueche, The Journal of Chemical Physics, 16, 573 (1948), https://doi.org/10.1063/1.1746948

29 T. Heinze and A. Koschella, Polímeros, 15, 84 (2005), $\quad$ http://dx.doi.org/10.1590/S010414282005000200005

30 E. Kontturi, Advanced Biomaterial Chemistry and Technology, 2015 , https://mycourses.aalto.fi/pluginfile.php/148341/mod_f older/content/0/Lecture\%204\%20- 
\%20Cellulose\%20dissolution.pdf?forcedownload=1

31 P. Bajpai, "Biotechnology for Pulp and Paper Processing”, Springer, Singapore, 2011, pp. 414, https://www.springer.com/gp/book/9789811078521

32 T. Sawoszczuk, P. Wandelt, A. Barański, J. M. Łagan and T. Łojewski, in Procs. International Conference "Durability of Paper and Writing", Ljubljana, Slovenia, November 16-19, 2004, pp. 78-80

${ }_{33}$ G. Eymin-Petot-Tourtollet, F. Cottin, A. Cochaux and M. Petit-Conil, in Procs. International Mechanical Pulping Conference, Québec City, Canada, June 2-5, 2003, pp. 225-232.

34 V. S. Chauhan, N. Kumar, M. Kumar and S. K. Thapar, Taiwan J. Forest Sci., 28, 51 (2013), http://www.ceps.com.tw/ec/ecJnlIntro.aspx?Jnliid=171 7

35 S. Adamopoulos and J. Oliver, Wood Fiber Sci., 38 , 567 (2006),

https://wfs.swst.org/index.php/wfs/article/view/2111/2 111

36 J. H. Woodward, Microsc. Microanal., 8, 196 (2002), https://doi.org/10.1017/S1431927602102303

37 T. Conners, "Distinguishing Softwoods from Hardwoods", Agriculture and Natural Resources Publications, 2015, p. 105, https://uknowledge.uky.edu/anr_reports/105
38 S. Asikainen, Thesis, VTT Technical Research Centre of Finland, 2015, p. 126, https://www.vttresearch.com/

39 S. Zhang, F.-X. Li and J.-Y. Yu, Cellulose Chem. Technol., $\quad 45, \quad 313 \quad$ (2011), http://www.cellulosechemtechnol.ro/pdf/CCT45,56(2011)/p.313-320.pdf

40 H. Qi, Q. Yang, L. Zhang, T. Liebert and T. Heinze, Cellulose, 18, $237 \quad$ (2011), https://doi.org/10.1007/s10570-010-9477-8

41 L. C. Yeng, M. U. Wahit and N. Othman, Jurnal $\begin{array}{llll}\text { Teknologi, } & \mathbf{7 5}, & 107 & \text { (2015), }\end{array}$ www.jurnalteknologi.utm.my

42 Y. P. Yang, Y. Zhang, Y. X. Lang and M. H. Yu, in Procs. IOP Conference Series: Materials Science and Engineering, 2017, p. 213, https://iopscience.iop.org/article/10.1088/1757899X/213/1/012039

43 Q. Yang, X. Qin and L. Zhang, Cellulose, 18, 681 (2011), https://doi.org/10.1007/s10570-011-9514-2 